\title{
Parieto-Occipital Artery
}

National Cancer Institute

\section{Source}

National Cancer Institute. Parieto-Occipital Artery. NCI Thesaurus. Code C33274.

An artery arising from the pericallosal artery that extends along the parieto-occipital

sulcus to supply the medial and superolateral surfaces of the parietal lobe and sometimes the occipital lobe. 